\title{
Socio-demographic, Clinical and Laboratory Characteristics of Melioidosis: Four-Year Experience of Managing Consecutive 11 Cases in a Tertiary Care Hospital of Bangladesh
}

\author{
Afroze $\mathrm{SR}^{\mathrm{a}}$, Barai L ${ }^{\mathrm{b}}$, Rahim MA ${ }^{\mathrm{c}}$, Haque $\mathrm{HF}^{\mathrm{a}}$, Afroz $\mathrm{F}^{\mathrm{a}}$, Hoque MT ${ }^{\mathrm{d}}$, Ahmed JU', Ahmed \\ $\mathrm{AKMS}^{\mathrm{f}}$, Hossain $\mathrm{MD}^{\mathrm{f}}$, Rahman $\mathrm{MR}^{\mathrm{f}}$, Musa AKM ${ }^{\mathrm{g}}$, Uddin $\mathrm{KN}^{\mathrm{g}}$
}

\begin{abstract}
Background: Melioidosis is caused by Burkholderia pseudomallei, a gram negative non-fermentative bacillus found in water and soil. Transmission to human is by contact and it causes disease mostly in the immunocompromised state. As melioidosis closely mimics tuberculosis it is often misdiagnosed and often empirically treated as tuberculosis. Increasing numbers of published cases among Bangladeshis and isolation of B. pseudomallei in the soil of Gazipur district has confirmed our country as a 'definite country for melioidosis'.

Methods: This study was carried out in the Department of Medicine, Bangladesh Institute of Research and Rehabilitation in Diabetes, Endocrine and Metabolic Disorders (BIRDEM) General Hospital, Dhaka, Bangladesh from September 2013 to September 2016. Adult patients with melioidosis confirmed by growth of B. pseudomallei from different specimens were included. Socio-demographic, clinical and laboratory characteristics were studied and treatment outcome was also documented.

Results: Total 11 cases including 9 males were detected with melioidosis during the study period. All cases were diabetic. Mean age was 39.73 years. Eight cases were classified as endemic while 3 patients returned from overseas. Four patients' (36.36\%) home district was Tangail. Common presentations were fever (100\%), cough $(45.45 \%)$, dysuria (36.36\%), cutaneous lesions (36.36\%) and septic shock (36.36\%). The common sites involved were skin (36.36\%), genitourinary tract (36.36\%) and lung (36.36\%) followed by joint (18.18\%). Ten cases (90.9\%) had neutrophilic leucocytosis with raised ESR/CRP in all cases. Culture of sixteen different specimens revealed growth of $B$. pseudomallei. In 6 a cases co-trimoxazole resistance was found in vitro. Common radiological findings showed lung involvement (36.36\%) and organ abscess (18.18\%). One patient was lost from follow up following discharge. Among the remaining 10 patients, 6 were declared cured, 1 patient improved and 3 patients died from septic shock. Ceftazidime/meropenem as initial therapy followed by a combination of doxycycline and trimethoprim-sulfamethoxazole or doxycycline and amoxicillin-clavulanic acid proved to be effective.
\end{abstract}

Conclusion: Observation revealed that this disease, if remained untreated, can cause life threatening complications, even death. Therefore, suspicion of melioidosis should be considered in appropriate clinical scenario.

Keywords: Bangladesh, BIRDEM, Burkholderia pseudomallei, melioidosis

(BIRDEM Med J 2017; 7(1): 28-37)

Authors information

a. Dr. Samira Rahat Afroze, Dr. Hasna Fahmima Haque, Dr. Farhana Afroz, Registrar, Department of Internal Medicine, BIRDEM General Hospital \& Ibrahim Medical College.

b. Dr. Lovely Barai, Associate Professor, Department of Microbiology, BIRDEM General Hospital.

c. Dr. Muhammad Abdur Rahim, Assistant Professor, Department of Nephrology, BIRDEM General Hospital \& Ibrahim Medical College.

d. Dr. Md. Tariful Haque, Senior Medical Officer, Department of Internal Medicine, BIRDEM General Hospital.

e. Dr. Jamal Uddin Ahmed, Assistant Professor, Department of Internal Medicine, BIRDEM General Hospital \& Ibrahim Medical College.

f. Dr. AKM Shaheen Ahmed, Md. Delwar Hossain, Md. Raziur Rahman, Associate Professor, Department of Internal Medicine, BIRDEM General Hospital \& Ibrahim Medical College.

g. Dr. AKM Musa, Khwja Nazim Uddin, Professor, Department of Internal Medicine, BIRDEM General Hospital \& Ibrahim Medical College. Address of correspondence: Dr. Samira Rahat Afroze, FCPS (Medicine), Registrar, Department of Internal Medicine, BIRDEM General Hospital \& Ibrahim Medical College, Dhaka, Bangladesh. Email: srafroze6@gmail.com

Received: January 1, 2016

Accepted: November 30, 2016 


\section{Introduction}

Melioidosis is an infectious disease caused by Burkholderia pseudomallei a gram negative bacillus which is a common soil and fresh water saprophyte, mostly found in the tropical and subtropical regions. ${ }^{1}$ Transmission to human is by inoculation, inhalation or ingestion and causes disease mostly in the immunocompromised conditions. ${ }^{2}$ It is endemic in parts of Southeast Asia and Northern Australia where it is of public health importance. ${ }^{3-6}$

South Asia, including Bangladesh, is predicted to bear $44 \%$ of the overall burden, as the large populations living here in areas harboring B. pseudomallei. ${ }^{7}$ Moreover, the burden of melioidosis in many tropical developing countries like ours is hidden and masked by underdevelopment of microbiological facilities, lack of relevant clinical and laboratory expertise ${ }^{8}$, and poor reporting systems. ${ }^{7}$ Furthermore, a delay in diagnosis and treatment with inappropriate antimicrobials may result in case fatality rates exceeding 70\%. ${ }^{9,10}$ Since the isolation of the bacterium in the soil of Gazipur district, Bangladesh in 2013, ${ }^{11}$ there have been an increasing number of reported cases of melioidosis in Bangladesh. ${ }^{12-19}$

This observational study is the first of its kind to focus on describing the clinical features, diagnostic proofs, treatment and outcome of melioidosis cases in Bangladesh.

\section{Methods}

This observational study was carried out in the Department of Medicine, Bangladesh Institute of Research and Rehabilitation in Diabetes, Endocrine and Metabolic Disorders (BIRDEM) General Hospital, Dhaka, Bangladesh from September 2013 to September 2016. Total 11 adult patients diagnosed with melioidosis were included during this study period. All cases were confirmed by growth of $B$. pseudomallei from different samples. Culture growth was susubsequently confirmed by biochemical test and latex agglutination kit (Melioidosis Research Center, Khon Kaen University, Thailand). Socio-demographic, clinical and laboratory characteristics of these cases were studied and treatment outcome was also documented.

Patients who showed resolution of clinical and laboratory parameters following completion of both initial and maintenance therapy were declared as 'cured'.
Cases that showed improvement in both clinical and laboratory parameters following initial treatment and is currently on maintenance therapy were labeled as 'improved'. The cases who showed improvement in both clinical and laboratory parameters following initial therapy during their hospital stay but following discharge missed their follow up visits during their maintenance therapy, were declared as lost from follow up. Clinical parameters following treatment included resolution of the presenting symptoms and signs. Laboratory parameters following treatment included normalization of complete blood count, erythrocyte sedimentation rate (ESR) and/or C-reactive protein (CRP), subsequent culture of the affected sample showed no growth of the causative organism and resolution of the abnormal radiological findings.

\section{Results}

\section{Demography}

A total of 11 cases of melioidosis were identified during this study period. One case was diagnosed in 2013, 8 in 2015 and 2 in 2016. Most cases (8, 72.7\%) were admitted during the rainy season (April to August) during the study period. Nine patients $(82 \%)$ were male and $2(18 \%)$ were female. Age of the patients ranged from 28 to 52 years with a mean age of 39.73 years. Seven $(63.6 \%)$ patients belonged to the $20-40$ year age group. Regarding risk factors for melioidosis, all were diabetic. Among them 9 were previously known cases of diabetes mellitus and the other 2 cases were newly detected as diabetic. Duration of the 9 known cases of diabetes mellitus at the time of diagnosis of melioidosis ranged from 5 months to 10 years (mean 68.6 months). Other risk factors for melioidosis included steroid intake for glomerulonephritis (1) and smoking (1). None of the patients had chronic kidney disease.

Occupational history among 9 male patients revealed 3 farmers $(27.3 \%)$. The 2 female patients were both housewives and had exposure to soil on bare feet. One unemployed male patient had a hobby of fishing on bare feet and was a substance abuser as well (Table I).

Eight cases were classified as endemic and 3 other patients were workers who returned from overseas. The 8 endemic cases came from 5 different districts of Bangladesh. Among them 4 patients came from central region of Bangladesh ( 1 from Ashulia of Dhaka District, 2 from Narayanganj District and 1 from Tangail 
District), 1 patient from the northern regions of Bangladesh (from Mymensingh District), 2 cases were from the southeast region (Feni district) and 1 case from the east region (Comilla District). The 3 workers returning from overseas were from Brunei, Singapore and Saudia Arabia. Interestingly, all 3 of them had their home district in Tangail and gave a history of visiting home within 2 years of the occurrence of melioidosis (Table I). Therefore, among the 11 cases total 4 (36.4\%) patients' home district was in Tangail (Figure 1).

Table I. Socio-demographic characteristics and risk factors in cases of melioidosis $(n=11)$

\begin{tabular}{|c|c|c|c|c|c|c|c|}
\hline & $\begin{array}{l}\text { Patient } \\
\text { (year) }\end{array}$ & $\begin{array}{c}\text { Age } \\
\text { (years) }\end{array}$ & Sex & $\begin{array}{c}\text { Risk } \\
\text { Factors }\end{array}$ & Occupation & $\begin{array}{c}\text { Home } \\
\text { District }\end{array}$ & $\begin{array}{l}\text { Others (Hobby, returning } \\
\text { worker etc.) }\end{array}$ \\
\hline 1 & Sep 2013 & 40 & Male & $\mathrm{DM}^{*}$ & Farmer & Narayanganj & \\
\hline 2 & April 2015 & 45 & Male & $\mathrm{DM}$ & Unknown & Tangail & \\
\hline 3 & May 2015 & 52 & Male & $\mathrm{DM}$ & Unknown & Narayanganj & \\
\hline 4 & June 2015 & 38 & Male & $\mathrm{DM}$ & Farmer & Feni & Glomerulonephritis \\
\hline 5 & June-July2015 & 537 & Male & $\begin{array}{c}\text { DM } \\
\text { smoker }\end{array}$ & Unemployed & Comilla & $\begin{array}{l}\text { Substance abuse } \\
\text { Fishing hobby on bare feet }\end{array}$ \\
\hline 6 & July 2015 & 28 & Male & DM & Carpenter & Tangail & RW** from Saudi Arabia \\
\hline 7 & July-Aug2015 & 537 & Male & $\mathrm{DM}$ & $\begin{array}{l}\text { Construction } \\
\text { worker }\end{array}$ & Tangail & $\begin{array}{l}\text { RW from Singapore } \\
\text { Swimming in village pond }\end{array}$ \\
\hline 8 & Aug 2015 & 49 & Female & $\mathrm{DM}$ & Housewife & Feni & Exposure to soil on bare foot \\
\hline 9 & Nov 2015 & 45 & Male & DM & Farmer & Mymensingh & \\
\hline 10 & July 2016 & 31 & Male & $\begin{array}{l}\text { DM (newly } \\
\text { detected) }\end{array}$ & Plumber & Tangail & RW from Brunei \\
\hline 11 & Sep 2016 & 35 & Female & $\mathrm{DM}$ & Housewife & $\begin{array}{l}\text { Dhaka } \\
\text { (Ashulia) }\end{array}$ & Exposure to soil on bare foot \\
\hline
\end{tabular}

*DM : diabetes mellitus

** RW : returning worker from overseas

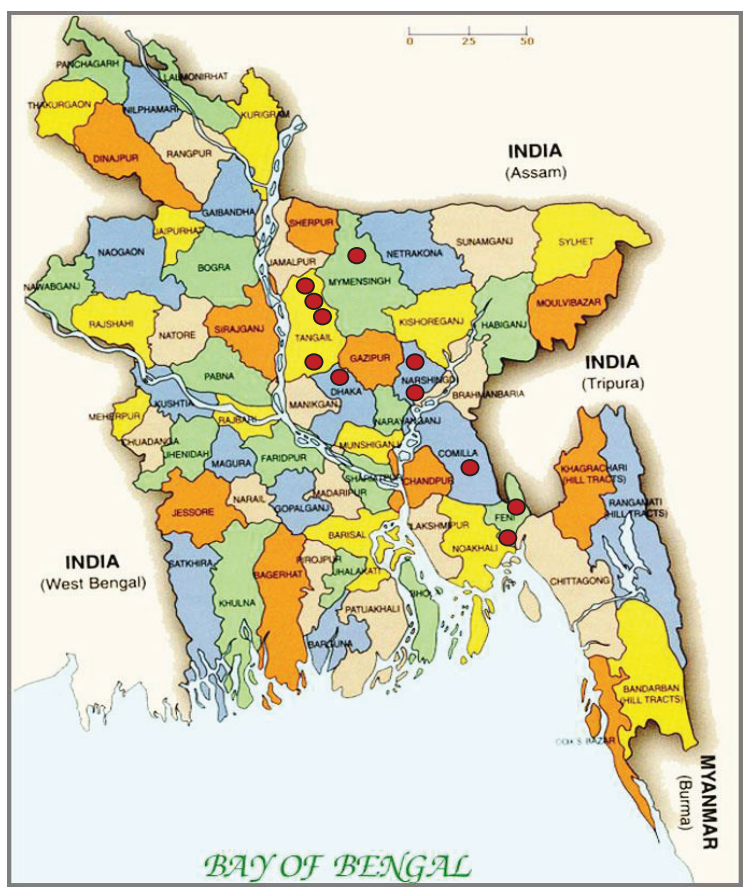

Figure 1. Map of Bangladesh showing site and distribution of home districts of the 11 patients. 


\section{Clinical data}

The most common presentation was fever $(11,100 \%)$, other features are shown in Table II. Duration of fever on admission ranged from 1 week to 2 months (mean 2.72 weeks).

Seven different sites were involved in the 11 cases of melioidosis (Table III). The common sites involved were skin $(4,36.36 \%)$, genitourinary tract $(4,36.36 \%)$ and lung $(4,36.36 \%)$ followed by joint $(2,18.18 \%)$. Five $(45.45 \%)$ out of 11 cases were disseminated melioidosis.

Table II. Clinical features of patients with melioidosis

\begin{tabular}{|c|c|c|}
\hline Clinical Features & Frequency & Percent \\
\hline Fever & 11 & 100 \\
\hline Cough & 5 & 45.45 \\
\hline Dysuria & 4 & 36.36 \\
\hline Cutaneous lesions & 4 & 36.36 \\
\hline Septic shock & 4 & 36.36 \\
\hline Anaemia & 4 & 36.36 \\
\hline Weight loss & 3 & 27.27 \\
\hline Arthritis & 2 & 18.18 \\
\hline Pleuritic chest pain & 2 & 18.18 \\
\hline Abdominal pain & 2 & 18.18 \\
\hline \multicolumn{3}{|c|}{ - Loin pain (1) } \\
\hline \multicolumn{3}{|c|}{ - left hypochondriac pain (1) } \\
\hline Diarrhoea & 1 & 9.09 \\
\hline Cellulitis & 1 & 9.09 \\
\hline SOB & 1 & 9.09 \\
\hline Back pain & 1 & 9.09 \\
\hline Band like chest pain & 1 & 9.09 \\
\hline Scrotal pain \& swelling & 1 & 9.09 \\
\hline Myalgia & 1 & 9.09 \\
\hline Headache & 1 & 9.09 \\
\hline Spinal shock & 1 & 9.09 \\
\hline Hepatomegaly & 1 & 9.09 \\
\hline Splenomegaly & 1 & 9.09 \\
\hline Lymphadenopathy & 1 & 9.09 \\
\hline Renal angle tenderness & 1 & 9.09 \\
\hline Ballotable kidney & 1 & 9.09 \\
\hline Splenic vein thrombosis & 1 & 9.09 \\
\hline $\mathrm{DKA}^{*}$ with $\mathrm{ACS} * *$ & 1 & 9.09 \\
\hline
\end{tabular}

*diabetic ketoacidosis

**acute coronary syndrome
Table III. Sites involved in patients with melioidosis

Site involved Frequency Percent

Cutaneous lesions

$4 \quad 36.36$

- Pustular (generalized in 1 case, over chest wall in 1 case )

- Abscess in leg (2)

Genitourinary tract infection (UTI) $\quad 4 \quad 36.36$

- Lower UTI (3)

- Renal abscess (1)

Lung involvement

$4 \quad 36.36$

- Cavity (1)

- Patchy opacities (2)

- Patchy opacitiy \& nodular shadow with hilar \& paratracheal lymphnodes (1) $\begin{array}{lll}\text { Joint (knee) } & 2 & 18.18\end{array}$ $\begin{array}{lll}\text { Infective spondylitis \& } & 1 & 9.09\end{array}$

Paravertebral abscess

$\begin{array}{lll}\text { Splenic abscess } & 1 & 9.09\end{array}$

\begin{tabular}{lll} 
Cellulitis (leg) & 1 & 9.09 \\
\hline
\end{tabular}

\section{Diagnosis}

All 11 cases $(100 \%)$ had leucocytosis , the white blood count (WBC) ranging from $12.7 \times 10^{9} / \mathrm{L}$ to $28.1 \times 10^{9} / \mathrm{L}$ (mean $19.2 \times 10^{9} / \mathrm{L}$ ). Neutrophil count was raised in 10 cases $(90.9 \%)$. Erythrocyte sedimentation rate (ESR) and/or C-reactive protein (CRP) was elevated in all 11 cases $(100 \%)$. Mean ESR was $74.6 \mathrm{~mm}$ in $1^{\text {st }}$ hour and mean CRP was $40.3 \mathrm{gm} / \mathrm{L}$. Random blood glucose on admission ranged from 11 to $26 \mathrm{mmol} / \mathrm{L}$ (mean 19.8 $\mathrm{mmol} / \mathrm{L}$ ) and $\mathrm{HbA} 1 \mathrm{c}$ ranged from $7.2 \%$ to $14.3 \%$ (mean $11.2 \%)$.

The mean WBC $\left(21.2 \times 10^{9} / \mathrm{L}\right)$, ESR $\left(76.6 \mathrm{~mm}\right.$ in $1^{\text {st }}$ hour) and $\mathrm{HbAlc}(12.1 \%)$ values in the 3 patients who expired was observed to be higher than the mean values of that $\left(18.4 \times 10^{9} / \mathrm{L}, 73.7 \mathrm{~mm}\right.$ in $1^{\text {st }}$ hour, $10.8 \%$ respectively) in the 8 patients who survived.

Acute kidney injury (AKI) occurred in 5 cases (45.45\%) as evidenced by raised serum creatinine. AKI resolved with treatment in 4 cases but one case expired within 24 hours of admission. Sixteen different clinical specimens (Table IV) revealed growth of $B$. pseudomallei. Among those half specimens were blood samples. Culture sensitivity pattern in six patients $(54.55 \%)$ showed co-trimoxazole resistance in vitro. In one case, stain was also confirmed by agglutination test and PCR. 
Table IV. Culture positive samples from patients with melioidosis

\begin{tabular}{|c|c|c|c|}
\hline & Frequency & percentage \\
\hline \multicolumn{2}{|l|}{$\frac{\text { Sample }}{\text { Blood }}$} & 8 & 72.73 \\
\hline \multirow[t]{3}{*}{ Pus } & & 3 & 27.27 \\
\hline & Cutaneous abscess (2) & & \\
\hline & FNAC* from paravertebral abscess (1) & & \\
\hline Urine & & 2 & 18.18 \\
\hline Synovial fluid & & 2 & 18.18 \\
\hline Sputum & & 1 & 9.09 \\
\hline
\end{tabular}

*Fine needle aspiration cytology

Common radiological findings showed lung involvement and organ abscess. Other findings included discitis with paravertebral abscess, splenic vein thrombosis, hepatomegaly and splenomegaly (Table V). Except for one lost from follow up case, radiological abnormalities in all other cases were resolved after treatment.

\begin{tabular}{|c|c|c|c|c|c|}
\hline Radiological & Site involved & Findings & Frequency & Percentage & Resolved after \\
\hline investigation & & & & & treatment \\
\hline \multirow[t]{5}{*}{ Chest xray } & Lung & Opacities & 3 & 27.27 & Yes in 2 cases \\
\hline & & & & & 1 case lost to follow up \\
\hline & & Cavity & 1 & 9.09 & Yes \\
\hline & & Nodular shadow & 1 & 9.09 & Yes \\
\hline & Lymphnodes & $\begin{array}{l}\text { Enlaged hilar \& } \\
\text { paratracheal }\end{array}$ & 1 & 9.09 & Yes \\
\hline \multirow[t]{3}{*}{$\begin{array}{l}\text { Ultrasonogram of } \\
\text { abdomen }\end{array}$} & Kidney & $\begin{array}{l}\text { Renal hypoechoic } \\
\text { SOL (abscess) }\end{array}$ & 1 & 9.09 & Yes \\
\hline & Liver & Hepatomegaly & 1 & 9.09 & Yes \\
\hline & Spleen & Splenomegaly & 1 & 9.09 & Yes \\
\hline \multirow[t]{2}{*}{$\mathrm{CT}$ of abdomen } & Spleen & $\begin{array}{l}\text { Splenic hypoechoic } \\
\text { SOL (abscess) }\end{array}$ & 1 & 9.09 & Yes \\
\hline & Splenic vein & $\begin{array}{l}\text { Splenic vein } \\
\text { thrombosis }\end{array}$ & 1 & 9.09 & Yes \\
\hline MRI spine & $\mathrm{D} 2$ to $\mathrm{D} 5$ & $\begin{array}{l}\text { Infective spondylitis } \\
\text { with paraspinal abscess } \\
\text { with intra- canalicular } \\
\text { extension causing } \\
\text { mild cord compression }\end{array}$ & 1 & $\begin{array}{ll}9.09 & \\
& \text { re }\end{array}$ & $\begin{array}{l}\text { Yes } \\
\text { Residual features of } \\
\text { esolved spondylo-discitis }\end{array}$ \\
\hline
\end{tabular}




\begin{tabular}{|c|c|c|}
\hline Case no. & Presenting features & Outcome \\
\hline 1 & Only septicaemia & Death \\
\hline 2 & $\mathrm{UTI}^{*}$ & Death \\
\hline 3 & $\mathrm{UTI}^{*}$ & Death \\
\hline 4 & Cutaneous lesion & $\begin{array}{l}\text { Lost from } \\
\text { follow up }\end{array}$ \\
\hline 5 & Splenic abscess & Cured \\
\hline 6 & $\begin{array}{l}\text { Cutaneous }+ \\
\text { paravertebral abscess }\end{array}$ & Cured \\
\hline 7 & $\begin{array}{l}\text { Septic arthritis }+ \text { cutaneous } \\
\text { pustular lesion+AKI** }\end{array}$ & Improved \\
\hline 8 & $\begin{array}{l}\text { Septic arthritis+ leg cellulitis } \\
\text { and abscess }+\mathrm{MI}^{\#}+\mathrm{DKA}^{\# \#} \\
+\mathrm{AKI}^{* *}\end{array}$ & Cured \\
\hline
\end{tabular}

* Urinary tract infection

**Acute kidney injury

\# Myocardial infarction

\#\# Diabetic keto acidosis

Table VII. Clinical diagnosis of cases without
septicemia with outcome
\begin{tabular}{lll} 
Case no. & Presenting features & Outcome \\
\hline 1 & UTI $^{*}+$ Glomerulonephritis on & Cured \\
2 & $\begin{array}{l}\text { Lung abscess, history of drug } \\
\text { abuse }\end{array}$ & Cured \\
3 & Left renal abscess & Cured \\
\hline
\end{tabular}

* Urinary tract infection

**Acute kidney injury

Among the 11 cases, 8 (72.7\%) of them had septicemia and the 3 patients who died belonged to this group. Five septicemia cases who survived also had other sites involved (Table VI). The other 3 cases who did not have septicemia had focal infections (Table VII).

\section{Treatment and outcome}

All patients were initially treated empirically with antibiotics after collecting samples and sending those for culture and sensitivity test. Meropenem was started in suspected severe cases of sepsis while ceftazidime was started in less severe cases. The standard regimen for melioidosis was initiated by adjusting the dose after being informed by our microbiology laboratory.
Among the 8 cases who survived, initial therapy consisted of intravenous ceftazidime in 4 patients and intravenous meropenem in 4 patients. Two cases receiving ceftazidime had to be switched to meropenem after 4 and 5 days respectively due to poor clinical response. One case receiving meropenem had to be swiched to ceftazidime with oral ciprofloxacin due to poor clinical response. The duration of initial therapy ranged from 3 to 6 weeks (Table VIII). Two patients required intensive care support during their initial therapy. Both cases were disseminated melioidosis with multi-organ failure, one of them also suffered from diabetic ketoacidosis and acute coronary syndrome. All 8 cases showed improvement in clinical and laboratory parameters during this period of initial therapy.

Table VIII. Treatment given (Initial acute phase)

\begin{tabular}{|c|c|c|c|}
\hline Antibiotics & Dose & Duration & Cases \\
\hline \multirow[t]{2}{*}{ Ceftazidime } & $50-100 \mathrm{mg} / \mathrm{kg}$ & 2 to 6 weeks & 2 \\
\hline & 2 gm 8 hrly & & \\
\hline \multirow[t]{2}{*}{ Meropenem } & $25-50 \mathrm{mg} / \mathrm{kg}$ & 3 to 4 weeks & 3 \\
\hline & 1 gm 8 hrly & & \\
\hline Ceftazidime & Do & 4 weeks & 2 \\
\hline \multirow{2}{*}{\multicolumn{4}{|c|}{$\begin{array}{l}\text { switched to } \\
\text { meropenem }\end{array}$}} \\
\hline & & & \\
\hline Meropenem & Do & 6 weeks & 1 \\
\hline \multicolumn{4}{|l|}{ followed by } \\
\hline ceftazidime & & & \\
\hline
\end{tabular}

Three out of the above 8 cases were co-trimoxazole sensitive. They were given combination of doxycycline and co-trimoxazole as maintenance therapy. Duration of prescribed maintenance therapy ranged from 3 months to 5 months (Table IX). Among these 3 patients, 2 cases were declared as cured. The other case who was lost from follow up following discharge returned to his workplace in Saudi Arabia.

Five out of 8 cases showed co-trimoxazole resistance by disc diffusion methods. As maintenance therapy 2 cases were prescribed a combination of doxycycline and augmentin with a duration of 3 months in one case and 10 months in the other (Table IX). The latter case was quite challenging, having disseminated melioidosis involving the spine with features of compressive myelopathy. This patient, at the $5^{\text {th }}$ month of his maintenance therapy required an additional intravenous ceftazidime and oral ciprofloxacin for $3 \frac{1}{2}$ months. Both cases were declared cured at the completion of their treatment. 
Table IX. Treatment given (Eradication phase)

\begin{tabular}{|c|c|c|c|}
\hline Antibiotics & Dose & Duration & Cases \\
\hline $\begin{array}{l}\text { Doxycycline } \\
+ \\
\text { Co-trimomazole }\end{array}$ & $\begin{array}{l}1 \mathrm{tab}(100 \mathrm{mg}) 12 \text { hrly } \\
(4 \mathrm{mg} / \mathrm{kg}) \\
+ \\
2-3 \mathrm{tab}(80-160 / 400- \\
800 \mathrm{mg}) \text { every } 12 \text { hrly }\end{array}$ & 3 to 5 months & 3 \\
\hline $\begin{array}{l}\text { Doxycycline } \\
+\end{array}$ & $\begin{array}{l}1 \text { tab }(100 \mathrm{mg}) 12 \text { hrly } \\
(4 \mathrm{mg} / \mathrm{kg})\end{array}$ & 3 months & 1 \\
\hline $\begin{array}{l}\text { Amoxicillin/ } \\
\text { clavulanic acid }\end{array}$ & $\begin{array}{l}+ \\
2-3 \text { tab every } 8 \text { hrly } \\
(500 \mathrm{mg} / 125 \mathrm{mg})\end{array}$ & & \\
\hline $\begin{array}{l}\text { Doxycycline } \\
+ \\
\text { ciprofloxacin }\end{array}$ & $\begin{array}{l}\text { Do }+ \\
1 \text { tab }(750 \mathrm{mg}) \text { every } 12 \\
\text { hrly }\end{array}$ & 3 to 4 months & 2 \\
\hline $\begin{array}{l}\text { Doxycycline+ } \\
\text { ciprofloxacin }+ \\
\text { Co-amoxyclav }\end{array}$ & Do & 4 to 10 months & 2 \\
\hline
\end{tabular}

The other 3 co-trimoxazole resistant cases were prescribed a maintenance therapy of and oral ciprofloxacin for 3 months (Table IX) . Among them 2 patients was declared as cured and the other patient is currently on her medications and responding well too.

The remaining 3 cases (out of the 11 cases) who expired within 12 - 24 hours of hospital admission and prior to culture reports were available, presented with septic shock. They were treated with ceftazidime 1 gm 8 hourly (in 2 cases) and ceftriaxone $1 \mathrm{gm} 12$ hourly (in 1 case). All 3 patients had septicemia and their blood culture \& sensitivity reports showed that one of them was cotrimoxazole resistant in vitro.

All 8 cases who responded to treatment (cured, improved and lost to follow up) comprised of $72.7 \%$ response rate as a whole (Table VI \& VII). The duration of treatment in both initial acute phase and eradication phase depended on the patients' clinical and laboratory responses and was individualized. In cases with AKI, doses were adjusted accorging to creatinine clearance rate.

So, in a nutshell, out of 11 patients 1 case was lost to follow up. Among the remaining ten patients, 6 were declared as cured and 1 patient as improved. Despite treatment 3 patients died due to complications of septic shock within 24 hours of admission and before the culture reports were available.

\section{Discussion}

Melioidosis can be difficult to diagnose due to its diverse clinical manifestations and inadequacy of conventional bacterial identification methods. ${ }^{7}$ Moreover, clinical, radiological and pathological similarities with tuberculosis may result in overlooking newly emerging diseases like melioidosis in tuberculosis endemic areas. In such circumstances, the role of the microbiologists and supportive equipments to diagnose the organism in the department of a hospital or health care delivery center is crucial.

In BIRDEM General Hospital we are fortunate to have a well developed microbiology laboratory as well as an effective team of clinical microbiologists. Since 2014, all 11 reported cases ${ }^{12-19}$ of melioidosis in Bangladesh were from our hospital. Moreover, as a renowned specialized center for diabetic patients, this hospital deals with various complications along with diabetes, which might also explain the dominance of number of diagnosed melioidosis cases here. 
Most of the diagnosed cases of melioidosis $(8,72.7 \%)$ were admitted during the rainy season (April to August). Epidemiologic data suggests that massive volumes of rainfall can result in a raise of the water level on land, which in turn leads to the accumulation of $B$. pseudomallei on surface soil. This water level then becomes a reservoir for inhalation of aerosolized bacteria for human and animal. Moreover, flooding may facilitate dynamic distribution of $B$. pseudomalle $i$ in the environment and thereby increase bacterial infective load both in surface water and soil. In addition, bacterial cells might be carried far away from their reservoirs to contaminate other water sources and farms. ${ }^{20-22}$

In this study, males were more affected (82\%). This might be due to the fact that males were more exposed to the bacterial reservoir environment owing to their different occupations, such as in exposure to soil during farming and inhalation of contaminated dust. The maleto-female ratio for melioidosis was also higher in all studies performed in Malaysia, Australia, and Singapore. ${ }^{23-25}$ Almost one-third of our patients were farmers. Majority of cases with melioidosis were also diagnosed in farmers in studies from Thailand and Malaysia $^{5,24}$. Melioidosis has been also been reported in construction workers in a study from Singapore ${ }^{25}$ and one of our patients was a returned construction worker from Singapore. One patient in our study who was unemployed had a history of drug abuse and fishing hobby. Melioidosis has been observed in patients associated with recreational activities resulting in exposure to environmental B. pseudomallei in Northern Australia in $75 \%$ cases. $^{23}$

Although surveys have shown the disease occurring in middle-aged patients ${ }^{23,24}, 63.6 \%$ of our patients belonged to the 20-40 years age group. All 11 cases in this study were diabetic and had uncontrolled blood sugar level. Case control studies show a relative risk of 5.9 to 13.1 among diabetic patients (mostly type 2). ${ }^{2}$ Regarding area of residence, $36.7 \%$ of the patients had their home district in Tangail. The 3 returning workers also belonged to this group. As Brunei, Saudi Arabia and Singapore are also endemic countries for melioidosis ${ }^{7}$, it is uncertain whether those patients had acquired the infection from their home district (Tangail) or their workplace. Serological evidence in Bangladeshi population ${ }^{26}$ also supports the fact that other districts of the country are also endemic for melioidosis.
All patients presented with fever $(100 \%)$. Among the 11 cases $72.7 \%$ had septicemia, $36.4 \%$ cases presented with septic shock and most cases had lung, skin and genitourinary involvement. In a 20 -year prospective Darwin study 21\% patients had septic shock and most cases also showed lung, skin and genitourinary involvement. ${ }^{23}$ Both cases of septic arthritis $(18.2 \%)$ in our study had bacteraemia. The reason behind the lowrate involvement of osteoarticular tissue in melioidosis might be attributed to the low blood supply to these locations comparing to other organs and knee joint is the most commonly affected joint. ${ }^{27}$

Melioidosis also can be misdiagnosed as tuberculosis due to similarities in clinical and laboratory findings between the two conditions. Our case of spinal melioidosis had radiological findings in MRI spine similar to Pott's disease. Subsequent evidence of $B$. pseudomallei from the affected area ruled out tuberculosis. Neurological melioidosis is less common as described in a study from Australia. ${ }^{27,28}$

There are technical difficulties in assessing the susceptibility of B. pseudomallei to co-trimoxazole. ${ }^{29}$

More than half $(6,54.55 \%)$ of the cases showed cotrimoxazole resistant in vitro. Having the culture reports in hand, the patients were treated accordingly. Subsequent sub-culture of the samples were further evaluated by MIC and co-trimoxazole resistance was later over-ruled. Five $(45.45 \%)$ out of 11 cases had disseminated melioidosis and all survived after treatment.

Possible reasons of death from complications of septic shock in 3 patients could be due to delay in approaching a tertiary health care center, initial inadequate dose of antibiotic and missed/delayed diagnosis prior to admission. In a 15-year review study in Malaysia 13 patients $(8.2 \%)$ who received empirical initial treatment failed to survive. ${ }^{30}$

In Bangladesh, with a $163,405,574$ population, $7.4 \%$ of them being diabetic, $83.53 \%$ of it's land being agriculture land and having a significant number of chronic kidney disease patients, one can easily assume that melioidosis in our country so far has been underdiagnosed and under-reported.

\section{Conclusion}

In this study our observation revealed that if melioidosis remains untreated it can cause life threatening complications, even death. On the other hand, if such 
cases are diagnosed and treated promptly, it is life saving and a good outcome can be expected. As melioidosis is an emerging infectious disease in Bangladesh, awareness among clinicians and microbiologists in Bangladesh is required. Population based studies are also required to detect the magnitude and extent of this disease in our country. Suspicion of melioidosis should be considered in appropriate clinical scenario, especially in patients living in or returning from melioidosis endemic countries.

\section{Conflict of interest: None}

\section{References}

1. Adler NRL, Govan B, Cullinan M, Harper M, Adler B, Boyce JD. The molecular and cellular basis of pathogenesis in melioidosis: how does Burkholderia pseudomallei cause disease? FEMS Microbiol Review. 2009; 33: 1079-99.

2. Cheng AC, Currie BJ. Melioidosis: Epidemiology, Pathophysiology, and Management. Clinical Microbiol Reviews. 2005; 18(2): 383-416.

3. Currie BJ, Fisher DA, Howard DM, Burrow JN, Lo D, SelvaNayagam $\mathrm{S}$ et al. Endemic melioidosis in tropical Northern Australia: a 10 year prospective study and review of the literature. Clin Infect Dis 2000; 31: 981-86.

4. Puthucheary SD, Parasakthi N, Lee MK. Septicaenic melioidosis: a review of 50 cases from Malaysia. Trans $\mathrm{R}$ Soc Med Hyg 1992; 86: 683-85.

5. Suputtamonkol Y, Hall AJ, Dance DAB, Chaowagul W, Rajchanuvong A, Smith MD, et al. The epidemiology of melioidosis in Urbon Ratchatani, Northern Eastern Thailand. Int J Epidemiol. 1994; 23: 1082-89.

6. Heng BH, Goh KT, Yap EH, Loh H, Yeo M. Epidemiological surveillance of melioidosis in Singapore. Ann Acad Med Singapore 1998; 27: 478-84.

7. Limmathurotsakul D, Golding N, Dance DAB, Messina JP, Pigott DM, Moyes CL, et al. Predicted global distribution of Burkholderia pseudomallei and burden of melioidosis. Nat Microbiol. 2016 Jan 1; 1(1): 15008.

8. Hoffmaster AR, AuCoin D, Baccam P, Baggett HC, Baird R, Bhengsri S, et al. Melioidosis Diagnostic Workshop, 2013. Emerg Infect Dis. 2015 Feb; 21(2): e141045.

9. White NJ, Dance DA, Chaowagul W, Wattanagoon Y, Wuthiekanun V, Pitakwatchara N. Halving of mortality of severe melioidosis by ceftazidime. Lancet. 1989; 23(2): 697701.

10. Lipsitz R, Garges S, Aurigemma R, Baccam P, Blaney DD, Cheng AC et al. Workshop on treatment of and postexposure prophylaxis for Burkholderia pseudomallei and B. mallei infection, 2010. Emerg Infect Dis. 2012 Dec; 18(12): e2.

11. Jilani MSA, Robayet JAMR, Mohiuddin M, Hasan MR, Ahsan CR, Haq JA. Burkholderia pseudomallei: Its Detection in Soil and Seroprevalence in Bangladesh. PLoS Negl Trop Dis. 2016 Jan; 10(1): e0004301.

12. Barai L, Jilani SA, Haq JA. Melioidosis-Case reports and review of cases recorded among Bangladeshi population from 1988-2014. Ibrahim Med Coll J. 2014; 8(1):25-31.

13. Mahbub S, Al-Amin Z, Biswas SS, Jamal MS, Halder S. Melioidosis - A Rare Infectious Disease with Atypical Presentation. Bangladesh J Otorhinolaryngol. 2014; 20(1): 46-49.

14. Afroze SR, Rahim MA, Barai L, Uddin KN. Disseminated melioidosis involving skin and joint: a case report. Ibrahim Med. Coll. J. 2015; 9(2): 55-57.

15. Fatema K, Faruq MO, Ahsan ASMA, Ahmed F, Shaha DK, Afroz F, et al. Dissiminated melioidosis presenting as septic shock: an endemic disease of Bangladesh. Int J Cur App Sci. 2015; 5(3): 200-202.

16. Rahim MA, Afroze SR, Barai L, Uddin KN. Melioidosis : Truly uncommon or uncommonly diagnosed in Bangladesh? A case report. Birdem Med J. 2015; 5(sup 1): 49-51.

17. Fatema K, Ahsan ASMA, Barai L, Shaha DK, Afroze SR, Faruq MO, et al. A Case of Fatal Melioidosis presenting as Septic Arthritis and Septicemia. Bangladesh Crit Care J. 2015; 3(2): 74-76.

18. Shaha DK, Ahsan ASMA, Faruq MO, Fatema K, Ahmed F, Saha M. Hepatic Abscess as Presenting Feature of Melioidosis: A Case Report. Birdem Med J. 2016; 6(1): 43-45.

19. Afroze SR, Rahman MR, Barai L, Hossain MD, Uddin KN. Successful treatment outcome of primary melioidosis pneumonia a case report from Bangladesh. BMC Res Notes (2016) 9:100.

20. Hare M, Thummasaeng K, Suriyajantra-Tong W, Wongpichet K, Saengkham M, Tatsapong P, et al. Pasture grass and legume evaluation on seasonally waterlogged and seasonally dry soils in north-east Thailand. Tropical Grasslands. 1999; 33: 6574.

21. Suputtamongkol Y, Chaowagul W, Chetchotisakd P, Lertpatanasuwun N, Intaranongpai S, Ruchutrakool T, et al. Risk factors for melioidosis and bacteremic melioidosis. Clin Infect Dis. 1999; 29(2): 408-13.

22. Sam IC, Puthucheary SD. Melioidosis and rainfall in Kuala Lumpur. Malaysia J Infect. 2007; 54(5): 519-20.

23. Currie BJ, Ward L, Cheng AC. The epidemiology and clinical spectrum of melioidosis: 540 cases from the 20 year Darwin prospective study. PLoS Negl Trop Dis. 2010; 4(11): e900.

24. Hassan MR, Pani SP, Peng NP, Voralu K, Vijayalakshmi N, Mehanderkar R, et al. Incidence, risk factors and clinical epidemiology of melioidosis: a complex socio-ecological emerging infectious disease in the Alor Setar region of Kedah, Malaysia. BMC Infect Dis. 2010; 10: 302.

25. Lo TJ, Ang LW, James L, Goh KT. Melioidosis in a tropical city state, Singapore. Emerg Infect Dis. 2009; 15(10): 1645 47. 
26. Maude RR, Maude RJ, Ghose A, Amin MR, Islam MB, Ali $\mathrm{M}$, et al. Seroepidemiological surveillance of Burkholderia pseudomallei in Bangladesh. Trans R Soc Trop Med Hyg. 2012 Sep; 106(9): 576-78.

27. Morse LP, Smith J, Mehta J, Ward L, Cheng AC, Currie BJ. Osteomyelitis and septic arthritis from infection with Burkholderia pseudomallei: A 20-year prospective melioidosis study from northern Australia. J Orthop. 2013; 10(2): 86-91.
28. Currie BJ, Fisher DA, Howard DM, Burrow JN. Neurological melioidosis. Acta Trop 2000; 74: 145-51.

29. Dance D. Treatment and prophylaxis of melioidosis. Inter J of Antimicrobial Agents. 2014; 43: 310-18.

30. Zueter1 AR, Yean CY, Abumarzouq M, Rahman ZA, Deris ZZ, Harun A. The epidemiology and clinical spectrum of melioidosis in a teaching hospital in a North-Eastern state of Malaysia: a fifteen year Review. BMC Infect Dis. 2016; 16: 333. 